\title{
AN EVALUATION INSTRUMENT FOR COLLABORATIVE PROCESSES: APPLICATION TO ORGANIZATIONAL POLICY-MAKING
}

\author{
JOSEPHINE NABUKENYA \\ Institute of Computing and Information Sciences, Radboud University Nijmegen, Toernooiveld 1, 6525 ED, \\ Nijmegen, the Netherlands, \\ josephine@cs.ru.nl \\ PATRICK VAN BOMMEL \\ Institute of Computing and Information Sciences, Radboud University Nijmegen, Toernooiveld 1, 6525 ED, \\ Nijmegen, the Netherlands \\ P.vanBommel@cs.ru.nl \\ H. A. (ERIK) PROPER \\ Institute of Computing and Information Sciences, Radboud University Nijmegen, Toernooiveld 1, 6525 ED, \\ Nijmegen, the Netherlands \\ E.Proper@cs.ru.nl \\ GERT-JAN DE VREEDE \\ College of Information Science \& Technology, University of Nebraska at Omaha, 6001 Dodge \\ Street, \\ Omaha, NE 68182, USA \\ gdevreede@mail.unomaha.edu \\ Faculty of Technology, Policy and Management, Delft University of Technology, Postbus 5, \\ 2600 AA Delft, The Netherlands \\ Received Day Month Year \\ Revised Day Month Year \\ Decision-making in organizations is guided by policies. Organizational policy-making is a complex \\ process in which several parties are involved, with multiple backgrounds, incompatible interests, and \\ diverging areas of interest, yet they all have to be brought together to produce an acceptable policy \\ result. Therefore, we propose to use techniques from collaboration engineering (CE) in this context. \\ There is hardly any experience with CE in the field of organizational policy-making. In order to \\ evaluate the effectiveness and efficiency of $\mathrm{CE}$ in organizational policy-making, it is important to \\ have a systematic evaluation instrument. We distinguish between general and domain-specific \\ indicators. Moreover, we consider measurement means and operationalization tools, such that \\ organizational policy-making stakeholders can apply our instrument in their own organization. \\ Key words: Collaboration Engineering, Organizational policy-making, and Evaluation,
}




\section{Introduction}

Today, organizations have joined the spirit of collaboration in order to create more value for their stakeholders. Substantial productivity gains can be achieved as a result of collaborative effort. ${ }^{1}$ The notion of collaboration is defined by Ref. 2, as "making a joint effort toward a goal". Despite organizations engaging in collaboration, the success of their efforts still remains a challenge. They consume time and resources without necessarily creating substantial value. ${ }^{3}$

To maximize the focus of purposeful effort (collaboration) therefore, we turn to the field of Collaboration Engineering (CE). CE involves the design of recurring collaboration processes that are meant to cause predictability and success among organizations' recurring mission-critical collaborative tasks. ${ }^{1}$ To realize their success, evaluation of the designed collaboration processes is vital. This is because we want to maximize the focus of purposeful effort; evaluate return on investment; improve a process design; create substantial value for the organization; and also to reduce complexity of problem-solving process.

The concept of evaluation has been defined by Ref. 4, as the "process of determining the merit, worth, or value of something, or the product of that process". Ref. 5, define evaluation as "the systematic application of social research procedures for assessing the conceptualization, design, implementation, and utility of ... programs". While Ref. 6, describes evaluation in two ways: First he describes evaluation using the most given definition "the systematic assessment of the worth or merit of some object". According to Trochim, this definition emphasizes on assessment of worth or merit, yet many types of evaluations do not necessarily result into this. Examples of these include descriptive studies, implementation analyses and formative evaluations. Trochim therefore suggests a definition that emphasizes information-processing and feedback functions of evaluation. That is, "evaluation is the systematic acquisition and assessment of information to provide useful feedback about some object". To Trochim, both definitions agree that evaluation is a systematic endeavor, yet use the notion of object. To acquire and assess information would rather be emphasized to assessing worth or merit. This is because irrespective of whether or not an assessment of worth or merit results, all evaluations involve collection, sorting data, judgments of validity of information and of inferences derived from it. ${ }^{6}$

For our purpose we will use the most frequently given definition of evaluation as the systematic process of determining the merit, value, and worth of some object. ${ }^{4,7}$ It is a way of measuring if that object is doing what it says it will do. More importantly, we are looking at evaluating a collaboration process; we are interested in how well the process is working and whether its meets its intended goal. That is, we want to evaluate how to realize a quality process and outcome of this process, in a collaborative organizational policy-making effort. Accurate measurement is essential to assess the impact of a collaboration intervention. ${ }^{9}$ In the collaboration engineering field of research, evaluation of a collaboration effort is done by making a distinction between the design object (the collaboration process) and the design process. ${ }^{1}$ 
Organizational policy-making process is a complex ill-structured and messy problem-solving process ${ }^{10}$, that no single person has all the understanding, information and resources to do it alone. This complexity can be described as the involvement of a variety of actors resulting in a situation where multiple backgrounds, incompatible interests, diverging areas of interest, and conflicting objectives and criteria, all have to be brought together to produce an acceptable policy result. The process of policy-making needs to be made easy and structured especially for stakeholders involved, yet derive value to the organization. The term stakeholder refers to all those individual actors and parties, organized groups and professions, and institutions that have a bearing on the behavior of the organization as revealed in its policies and actions on the environment. ${ }^{11}$ Organizations and their stakeholders need to have a standard collaboration process, that is, a well-defined process specification with several choices depending on the context/situation in which a policy needs to be specified, that is referred to when making policies. Policies are everyday happenings of organizations, that is, there is always a problem to solve that may require a new policy to be put in place. $\mathrm{CE}$ is an approach to designing such recurring collaborative organizational policy-making processes. This relationship is illustrated in Figure 1 below: 


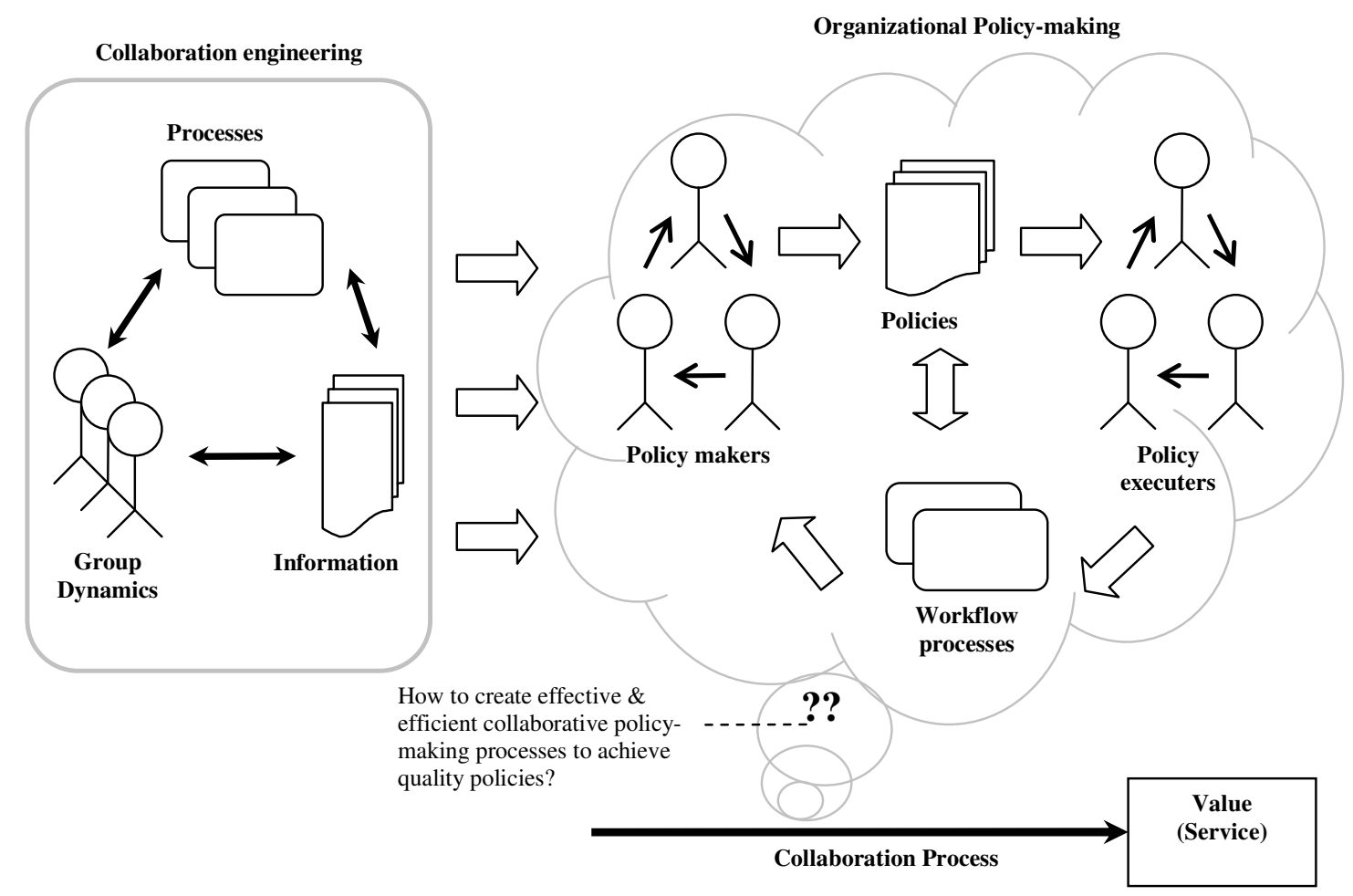

Fig. 1: Collaboration engineering for Organizational policy-making

Figure 1 depicts an organization with a challenge of how groups of policy-makers and executers (shown in the right-hand side) can create effective and efficient collaborative policy-making processes that occur often in related fashions to realize acceptable policy results. To address this challenge, we introduce an evaluation instrument following the $\mathrm{CE}$ approach (shown in the left-hand side). The intention of the collaboration process is to generate additional value (shown at the bottom of Figure 1).

The purpose of this paper therefore, is to provide an evaluation instrument consisting of domain independent and specific measures for collaborative processes including its application to organizational policy-making. The instrument is targeted at providing measurement means and operationalization tools examples that organizations can use to evaluate and realize effective and efficient collaboration processes towards achieving a goal. Specifically, the evaluation instrument is to address the complexity (i.e. collaborative concerns) for organizational policy-making processes. The instrument can be used to benchmark and perform an assessment of a collaboration intervention, thus supporting continuous improvement of collaborative policy-making processes.

The remainder of this paper is structured as follows: section 2 gives an overview of the CE approach and highlights of examples of collaboration processes that have been 
designed following the CE approach. This is followed by an assessment of and evaluation framework for collaboration processes general and domain indicators in section 3 . In section 4, a description of the concept of Policy, policy-making processes, and policymaking as a collaborative process is given; followed by an evaluation framework for collaborative organizational policy-making processes in section 5, and finally, a conclusion is made with suggestions of future research in section 6 .

\section{Overview of the Collaboration Engineering (CE) Approach}

Collaboration Engineering (CE) is an approach we claim to benefit organizations that wish to create more value for their stakeholders. Working together (collaboration) helps stakeholders to build on one another's ideas leveraging their different talents and knowledge. Also, they are more cable of providing a reality-check for proposed solutions than is the individual proposing a solution. Further more, when all the stakeholders are represented in creative problem-solving activities, there is a better chance their interests will be accommodated in the solution. ${ }^{12}$ To achieve mutually desired outcomes, organization stakeholders need to combine their efforts (collaborate). Collaboration Engineering is therefore defined by Ref. 1, as "an approach to designing collaborative work practices for high-value recurring tasks, and deploying those designs for practitioners to execute for themselves without ongoing support from professional facilitators".

In Ref. 1, to design recurring mission-critical collaboration processes for execution by practitioners, collaboration engineers need to follow a four ways model suggested by Ref. 13. The "four ways" model offers a comprehensive description of a method or approach. That is, the Seligmann framework ${ }^{13}$ is a framework to describe/define information systems development methods. When using this framework (see Figure1) for $\mathrm{CE}$, the way of thinking portrays how we observe the application domain of the design approach; the way of working describes the activities to be carried out in order to design the artifact under consideration (in our case a collaboration process); the way of modeling describes the techniques used to build and portray representations of relevant aspects of the design artifact; and finally, the way of controlling describes the measures and methods for managing the engineering process.

In addition to knowing the ways of designing collaborative mission-critical tasks, collaboration engineers also need to consider how a group will accomplish each task. To this end, a pattern of collaboration can be used as a means to determine how a group can move through the phases to attain a goal. As groups move through the phases, the patterns of collaboration characterize their activities. Six patterns of collaboration are defined in a way that they are meant to move a group from a starting state to an end state $^{14}$ : Generate (move from having fewer concepts to having more concepts); Reduce (move from having many concepts to having a focus on fewer concepts deemed worthy of further attention); Clarify (moving from less to more shared meaning for the concepts under consideration); Organize (move from less to more understanding of the relationships among the concepts); Evaluate: Move from less to more understanding of the benefit of concepts toward attaining a goal); and Build consensus (move from having 
more disagreement to having less disagreement among stakeholders on proposed courses of action).

Notwithstanding their role, the patterns of collaboration do not explicitly detail how a group could conduct a recurring collaboration process. In other words, specifications of how a particular pattern should be realized when a process is run by the group is lacking. This can be achieved by so-called thinkLets. Ref. 14, define a thinkLet as "a named, packaged facilitation intervention that creates a predictable, repeatable pattern of collaboration among people working together toward a goal". ThinkLets have several benefits to the design and transfer of collaboration processes: they permit ease of communication, documentation and transfer of a collaboration process to others; they improve productivity of and quality of work life for groups by enabling rapid development of collaboration processes; they also create particular dynamism within groups, though each instantiation of the pattern would differ from all other instantiations. $^{15,16}$

Given its overview, we realize that $\mathrm{CE}$ focuses on the design of collaboration processes that are of a recurring nature. It is beyond the scope of this paper to report on individual recurring collaboration processes that have succeeded in various sectors such as in financial services, defense and software development. Rather we will highlight examples as they give rise to the potentiality of the CE approach. These examples include but are not limited to: Requirements Negotiation ${ }^{17,18}$, Risk \& Control Self Assessment collaboration process ${ }^{1}$, Collaborative Usability Testing to Facilitate Stakeholder Involvement ${ }^{19}$, Collaborative Incident Response Planning Process ${ }^{20}$, and Collaborative Software Code Inspection Process. ${ }^{21}$

\section{Evaluation Instrument for Collaboration Processes}

\subsection{General Indicators}

Because the designs of recurring processes (collaboration processes) are intellectual capital for an organization ${ }^{1}$, it becomes necessary to perform an evaluation of their success or quality in order to: maximize the focus of purposeful effort; evaluate return on investment; improve a process design; meet project efficiency (measure and monitor the degree to which projects are on time and under budget); meet standard assessments of customer satisfaction (e.g. practitioners being able to execute the process by themselves, process attaining satisfactory results/goal, flexibility to adapt to work practices, etc...); create substantial value for the organization; reduce complexity of problem-solving process.

To measure the quality or success of the designed collaboration process, we offer measurement mean(s) and operationalization tool(s) examples for the following general indicators in Table 1. The constructs in Table 1 are based on the effects of the CE effort proposed by Ref. 14. In their research, however, they do not cater for the measurement means and how to operationalize these constructs. Only definitions and descriptions of these constructs are given. Our contribution therefore lies in the provision of the measurement means and how they can be operationalized. We use insights from the 
construct definitions and their descriptions to derive these tools. The general indicators include but are not limited to:

- Review the product, not the producer.

- Satisfaction

- Group productivity

- Repeatability

- Organizational Adoption rate

- The sustainability of deployed work practice

- Transferability

- Creativity of participants' contributions

- Perceived gain in collaboration process' efficiency

- Perceived gain in collaboration process' effectiveness

- Participant commitment

- $\quad$ Ease of use

In addition to evaluation indicators of collaboration processes, it would also be important to take note of evaluation of the outcome of the process (product). This evaluation highly depends on the experts, and problem owner. Other times the process evaluation results would derive impact to the process outcome. In general, such indicators include but are not limited to perceptions from participants, and problem owner on satisfaction with process outcome; value creation; effectiveness; creativity of results; completeness; correctness/validity; usefulness of results and understandability of results. ${ }^{9}$

We also want to note that in different situations, different indicators may be more or less significant to determine the quality of the CE process. The variation in significance for instance, may depend on the context for which a collaboration process is designed and therefore being used ${ }^{1}$; while other times the indicators could be relevant to all processes irrespective of the context. For instance, while the "commitment" indicator is very important especially at the beginning of a collaboration process, the "satisfaction" indicator is also very important especially at the end of the process and with respect to the outcomes. ${ }^{14}$ Taking "participant commitment" as an example, it is a very significant indicator because without seeking commitment from participants, then execution of a collaboration process becomes difficult if not in vain, as stated by Ref. 14, that "at the start of a collaboration process commitment of the participants and practitioners to execute the collaboration process is an important success factor"; better still, commitment from participants also creates acceptance yet deriving ownership of the collaboration process by the participants. Also, in other situations, some indicators may conflict, which may affect others, for example, higher "creativity" may need more time, hence, lower "efficiency". In summary, significance / importance levels of indicators may vary when evaluating collaboration processes.

Table 1. General Indicators for designed collaboration processes (based on Ref. 14.)

\begin{tabular}{ccll}
\hline $\begin{array}{c}\text { General } \\
\text { Indicator }\end{array}$ & Description(s) & $\begin{array}{l}\text { Measurement means } \\
\text { (Examples) }\end{array}$ & $\begin{array}{l}\text { Operationalization } \\
\text { Tools (Examples) }\end{array}$ \\
\hline Satisfaction & $\begin{array}{l}\text { An affective response with } \\
\text { respect to the attainment of }\end{array}$ & $\begin{array}{l}\text { The output achieved versus } \\
\text { output planned }\end{array}$ & $\begin{array}{l}\text { i). Session outcome } \\
\text { questionnaires with }\end{array}$ \\
\hline
\end{tabular}




\begin{tabular}{|c|c|c|c|}
\hline & $\begin{array}{l}\text { goals (process outcomes; } \\
\text { and the process by which } \\
\text { the outcomes were } \\
\text { attained) }\end{array}$ & & $\begin{array}{l}\text { participants, problem } \\
\text { owner, facilitator } \\
\text { ii). Focused interviews } \\
\text { with problem owner, and } \\
\text { participants }\end{array}$ \\
\hline $\begin{array}{l}\text { Group } \\
\text { productivity }\end{array}$ & $\begin{array}{l}\text { The outcomes achieved } \\
\text { over the resources used in } \\
\text { a collaborative process in } \\
\text { order to arrive at } \\
\text { satisfactory results }\end{array}$ & $\begin{array}{l}\text { i). Number (quantity), } \\
\text { uniqueness and importance } \\
\text { (of each unique) of } \\
\text { contributions } \\
\text { ii). Amount of resources used } \\
\text { to get results }\end{array}$ & $\begin{array}{l}\text { i). Transcribing } \\
\text { reports/data logs to } \\
\text { determine quantity and } \\
\text { quality of results from the } \\
\text { process } \\
\text { ii). Session process } \\
\text { questionnaires with } \\
\text { participants, and problem } \\
\text { owner }\end{array}$ \\
\hline Repeatability & $\begin{array}{l}\text { Different groups working } \\
\text { on different collaborative } \\
\text { tasks should produce } \\
\text { similar collaboration } \\
\text { patterns when they execute } \\
\text { the process; i.e. the same } \\
\text { process could be applied } \\
\text { successfully in each } \\
\text { workshop with different } \\
\text { groups and focusing on } \\
\text { different collaborative } \\
\text { tasks }\end{array}$ & $\begin{array}{l}\text { i). The extent to which the } \\
\text { same collaborative task can } \\
\text { be applied in different } \\
\text { organizations; or, with } \\
\text { different groups in same } \\
\text { organization } \\
\text { ii). When it is domain focus } \\
\text { within task; we measure the } \\
\text { extent to which different foci } \\
\text { in context of task, e.g. } \\
\text { different types of incidents in } \\
\text { IRP, or different types of } \\
\text { requirements in EasyWinWin, } \\
\text { can be applied }\end{array}$ & $\begin{array}{l}\text { i). Direct observations } \\
\text { ii). Focused interviews } \\
\text { with participants } \\
\text { iii). Documentary analysis }\end{array}$ \\
\hline $\begin{array}{l}\text { Organizational } \\
\text { Adoption rate }\end{array}$ & $\begin{array}{l}\text { The extent to which } \\
\text { organizational stakeholders } \\
\text { easily get used to the } \\
\text { collaboration process in } \\
\text { their work practices }\end{array}$ & $\begin{array}{l}\text { How long it takes an } \\
\text { organization to get used to the } \\
\text { process or actually uses it }\end{array}$ & $\begin{array}{l}\text { i). Focused interviews } \\
\text { ii). Documentary analysis }\end{array}$ \\
\hline $\begin{array}{l}\text { The sustainability } \\
\text { of deployed work } \\
\text { practice }\end{array}$ & $\begin{array}{l}\text { The use of the work } \\
\text { practice as the standard } \\
\text { way of executing the task } \\
\text { without ongoing support } \\
\text { from experts outside the } \\
\text { organization }\end{array}$ & $\begin{array}{l}\text { i). Practitioners executing the } \\
\text { process themselves without } \\
\text { external/expert facilitator } \\
\text { help; } \\
\text { ii). The collaboration process } \\
\text { being accepted/adopted as the } \\
\text { organizational standard } \\
\text { process } \\
\text { iii). Practitioners being able to } \\
\text { fix the collaboration process } \\
\text { when it is broken }\end{array}$ & $\begin{array}{l}\text { i). Direct observations } \\
\text { ii). Documentary analysis }\end{array}$ \\
\hline Transferability & $\begin{array}{l}\text { The extent to which } \\
\text { practitioners can be } \\
\text { successfully trained in } \\
\text { executing the collaboration } \\
\text { process and understand } \\
\text { how to execute it }\end{array}$ & $\begin{array}{l}\text { The collaboration process } \\
\text { should not cause a high } \\
\text { cognitive load on the } \\
\text { practitioner while executing it }\end{array}$ & $\begin{array}{l}\text { i). Direct observations } \\
\text { ii). Focused interviews } \\
\text { with practitioners }\end{array}$ \\
\hline $\begin{array}{l}\text { Creativity of } \\
\text { participants' } \\
\text { contributions }\end{array}$ & $\begin{array}{l}\text { The identification of } \\
\text { solutions that are feasible } \\
\text { to implement, and fall } \\
\text { outside the set of known } \\
\text { solutions }\end{array}$ & $\begin{array}{l}\text { i). New and unique solutions } \\
\text { ii). Appropriateness and } \\
\text { quality of solutions }\end{array}$ & $\begin{array}{l}\text { i). Transcribing } \\
\text { reports/data logs to } \\
\text { evaluate quality of results } \\
\text { from the process by } \\
\text { domain experts } \\
\text { ii). Session outcome } \\
\text { questionnaires with } \\
\text { problem owner }\end{array}$ \\
\hline $\begin{array}{l}\text { Perceived gain in } \\
\text { collaboration } \\
\text { process' } \\
\text { efficiency }\end{array}$ & $\begin{array}{l}\text { The degree to which there } \\
\text { is perceived savings of the } \\
\text { amount of resources } \\
\text { required for attainment of }\end{array}$ & $\begin{array}{l}\text { The actual resources used } \\
\text { versus planned resources, e.g. } \\
\text { Time (duration), effort, costs, } \\
\text { etc... }\end{array}$ & $\begin{array}{l}\text { i). Session process } \\
\text { questionnaires } \\
\text { ii). Focused interviews }\end{array}$ \\
\hline
\end{tabular}




\begin{tabular}{|c|c|c|c|}
\hline & the goal & & \\
\hline $\begin{array}{l}\text { Perceived gain in } \\
\text { collaboration } \\
\text { process' } \\
\text { effectiveness }\end{array}$ & $\begin{array}{l}\text { The extent to which there } \\
\text { is perceived effort for a } \\
\text { group to achieve its goal }\end{array}$ & $\begin{array}{l}\text { The quality of results in a } \\
\text { traditional way of doing } \\
\text { things versus quality of } \\
\text { results in a new way of doing } \\
\text { the same things }\end{array}$ & $\begin{array}{l}\text { i). Session outcome } \\
\text { questionnaires with } \\
\text { participants } \\
\text { ii). Focused interviews } \\
\text { with problem owner, and } \\
\text { participants } \\
\text { iii). Direct observations } \\
\text { iv). Quantitative outcome } \\
\text { analysis }\end{array}$ \\
\hline Ease of Use & $\begin{array}{l}\text { The collaboration process } \\
\text { should not be complex, } \\
\text { and should be easily } \\
\text { understood by } \\
\text { practitioners, i.e. the } \\
\text { process should be easy for } \\
\text { the practitioners to learn } \\
\text { and execute routinely }\end{array}$ & $\begin{array}{l}\text { Number of times a } \\
\text { collaboration process is } \\
\text { executed by practitioners with } \\
\text { ease e.g. being able to } \\
\text { modify, make reviews } \\
\text { routinely }\end{array}$ & $\begin{array}{l}\text { i). Direct observations } \\
\text { ii). Focused interviews } \\
\text { with participants }\end{array}$ \\
\hline $\begin{array}{l}\text { Participant } \\
\text { commitment }\end{array}$ & $\begin{array}{l}\text { An assumption of an } \\
\text { obligation to expend } \\
\text { resources to fulfill the } \\
\text { terms of a proposal }\end{array}$ & $\begin{array}{l}\text { i). Positive versus negative } \\
\text { remarks towards } \\
\text { accomplishment of the } \\
\text { execution of the process } \\
\text { ii). The willingness of } \\
\text { participants to commit their } \\
\text { time or any other resources } \\
\text { they have access to }\end{array}$ & $\begin{array}{l}\text { i). Direct observation } \\
\text { ii). Focused interviews } \\
\text { with participants }\end{array}$ \\
\hline
\end{tabular}

- The sustainability of deployed work practice - this construct is where a work practice is considered as the standard way of executing a task without additional support from experts outside the organization. This means that the practitioners of an organization perform/execute the collaborative tasks in the process without ongoing support from professional facilitators or even the collaboration engineers. ${ }^{14}$

- Satisfaction - the satisfaction construct has been defined by Ref. 22, in the Satisfaction Attainment Theory $(\mathrm{SAT})^{22}$ as an "effective arousal with a positive valance on the part of a participant towards a meeting." It is a good feeling about the meeting. In SAT, it is mentioned that a person could feel satisfaction of a meeting in two ways: the meeting outcomes (an affective arousal with a positive valance on the part of a participant with respect to that which was created or achieved in a meeting); and the process by which the outcomes were attained (an affective arousal with a positive valance on the part of a participant with respect to the procedures and tools used in a meeting).

- Perceived gain in collaboration process' efficiency - efficiency in general is a measure of how much useful output is produced with a given resource. ${ }^{9}$ Efficiency can also be described as the degree to which there is conservation of attention resources during the accomplishment of a goal. ${ }^{23}$ We use these aspects of efficiency to describe perceived gain in collaboration process' efficiency as the degree to which there is perceived savings of the amount of resources required for attainment of the goal. For example the time participants actually use for achieving the planned outcomes in a collaboration session.

- Perceived gain in collaboration process' effectiveness - we describe this construct as the perceived effort for a group to achieve quality outcomes. ${ }^{23}$ Ref. 9, refer to 
effectiveness as the extent to which the actual outcomes of a session coincide with the planned or desired outcomes.

- Group productivity - productivity is defined as the degree to which a team achieves its goal. ${ }^{22}$ According to the Focus Theory ${ }^{23}$, for a group to be productive, the team members must be able to engage in three processes: communication (how the use of data communication equipment to effect exchange of meanings among people would affect the participants' attention resources); deliberation (the cognitive processes required to form intentions with respect to the team goal); and information access (information helps in changing the expectations of the choice-maker in choice making activities but does not necessarily change the outcome of making a particular choice. Information is the content for both communication and deliberative processes). Each of these processes demands cognitive effort over time (attention). Thus, the reasoning of Focus Theory is that goal congruence motivates the focus of cognitive effort over time for communication, deliberation, and information access, which in turn causes productivity. We use insights of this theory to describe group productivity as the outcomes achieved over the resources used in a collaborative process in order to arrive at satisfactory results.

- Transferability - this construct is where a collaboration engineer transfers the collaboration process designed to practitioners for them to execute. A collaboration process is more easily transferable when the cognitive load for the practitioners is low. ${ }^{9}$ That is, the process should not cause a high cognitive load of the practitioners, as they need to concentrate on the content of the domain and group dynamics. ${ }^{12}$ Ref. 9, use the Technology Transition Model (TTM) (see Ref. 24) three constructs identified to describe cognitive load in the collaboration process perspective: Perceptual load (the ease of use of the process, that is, the amount of mental effort required to use the collaboration process); Conceptual load (the understandability, that is, the amount of effort required to understand what the collaboration process is supposed to do); Access load.(the availability of the technology as described in the TTM is referred to availability of resources, support, and information that practitioners need in the execution of a collaboration process). Based on these insights, we then describe transferability as the extent to which practitioners can be successfully trained in executing the collaboration process (find it easy to use) and understand how to execute it.

\subsection{Domain-specific Indicators}

Notwithstanding the general CE evaluation indicators for designed collaboration processes described above, we should acknowledge that they may not be complete. In that case, a collaboration engineer may identify domain-specific indicators for a particular collaboration process; or, in addition, indicators based on particular phenomena may be added depending on the phenomena of interest that the collaboration engineer is designing for. ${ }^{1}$ For example, the existing literature on respective cases (see section 2.0) shows that evaluation of the collaboration processes was not necessarily specific to the respective domains; most of the evaluation was guided by general independent indicators. To make their evaluation complete therefore, we draw on experiences from this literature to obtain domain-specific indicators examples as presented in Table 2. 
Table 2. Descriptions of Examples of Domain-specific Indicators

\begin{tabular}{|c|c|}
\hline $\begin{array}{c}\text { Collaboration Process } \\
\text { Name }\end{array}$ & Domain-specific Indicators \\
\hline $\begin{array}{l}\text { Risk \& Control Self } \\
\text { Assessment }\end{array}$ & $\begin{array}{l}\text { i. Timeliness definition and assessment of significant risks - the process } \\
\text { should permit stakeholders to easily identify significant areas of } \\
\text { potential risks. } \\
\text { ii. Ability to focus - stakeholders should be able to focus on most severe } \\
\text { risks by assessing risk exposure } \\
\text { iii. Completeness of the risk assessment process - fulfillment and } \\
\text { availability of relevant information for each of the elements of the } \\
\text { risk assessment process outcomes by stakeholders }\end{array}$ \\
\hline $\begin{array}{l}\text { Usability Testing to Facilitate } \\
\text { Stakeholder Involvement }\end{array}$ & $\begin{array}{l}\text { i. Perceived expectation accommodation - the ability of the process to } \\
\text { accommodate awareness of each stake holder's desired usability } \\
\text { capabilities } \\
\text { ii. Ability to focus - the ability of the process to accommodate the } \\
\text { expression of preferences by stakeholders } \\
\text { iii. Perceived benefit of the outcomes of the process - the ability of the } \\
\text { process to provide stakeholders with a quick and efficient way to } \\
\text { consider the best return-on-investment of proposed action items }\end{array}$ \\
\hline Requirements Negotiation & $\begin{array}{l}\text { i. Stakeholders' ease of defining requirements - ability of stakeholders } \\
\text { to identify what is desirable and what should be achieved } \\
\text { ii. Ease of requirements reviews - stakeholders should be able to } \\
\text { review the inclusion, levels, and quality of the formulated } \\
\text { requirement } \\
\text { iii. Comprehensiveness of problem treatment - stakeholders should be } \\
\text { able to investigate a full spectrum of alternative solutions before } \\
\text { making a decision }\end{array}$ \\
\hline Incident Response Planning & $\begin{array}{l}\text { i. Ability to focus - the process should enable stakeholders to easily } \\
\text { focus on severe incidents for response } \\
\text { ii. Completeness of the description of the planning process - the ability } \\
\text { of the stakeholders to fulfill and with relevant information for each of } \\
\text { the elements of the plan } \\
\text { iii. Correctness - the plan should enable stakeholders benefit from the } \\
\text { previous experiences }\end{array}$ \\
\hline $\begin{array}{l}\text { Collaborative Software code } \\
\text { Inspection }\end{array}$ & $\begin{array}{l}\text { i. Comprehensiveness of results - the process should be able to identify } \\
\text { different types of defects as defined before the inspection execution. } \\
\text { ii. Non-redundancy of results - the process should minimize the } \\
\text { redundancy of identified defects as much as possible. } \\
\text { iii. Applicability to varying quality of software code - the collaborative } \\
\text { inspection process should be effective for software code of different } \\
\text { quality. }\end{array}$ \\
\hline
\end{tabular}

\section{Collaborative Policy-making Processes}

\subsection{What is a Policy?}

The concept of policy has been defined by several researchers, though we will only provide a few definitions. Ref. 25, defines a policy as "a guide that establishes parameters for making decisions; it provides guidelines to channel a manager's thinking in a specific direction”. While Ref. 26, defines a policy as “a long series of more-or-less related activities" and their consequences for those concerned rather than as a discrete decision. 
Ref. 26's definition embodies the useful notion that policy is a course or pattern of activity and not simply a decision to do something. Ref. 27,28 , defines policy as "a purposive course of action followed by an actor or set of actors in dealing with a problem or matter of concern". Ref. 27, 28's concept of policy focuses attention on what is actually done as against what is proposed or intended, and it differentiates a policy from a decision, where the latter is a choice among competing alternatives. Whether in the public or private sector, policies also can be thought of as the instruments through which societies regulate themselves and attempt to channel human behavior in acceptable directions. ${ }^{29}$ To take into account the various perspectives of the concept of policy, we offer the following definition to help integrate them: a policy is a purposive course of action followed by a set of actor(s) to guide and determine present and future decisions, with an aim of realizing goals. ${ }^{30}$

\subsection{Policy-making processes}

To develop and implement a policy, organizational stakeholders follow a policy-making process. According to Ref. 31, the concept of policy-making process includes the manner in which problems get conceptualized and brought to the governing body for solution, these formulate alternatives and select policy solutions; and those solutions get implemented, evaluated, and revised. The policy-making process “connotes temporarily, an unfolding of actions, events, and decisions that may culminate in an authoritative decision, which, at least temporarily, binds all within the jurisdiction of the governing body". In explaining the policy-making process, Ref. 31, says that, the emphasis is much more on the unfolding than it is on the authoritative decision. In examining the unfolding, attention is devoted to structure, to the context and constraints of the process, and to actual decisions and events that occur. Ref. 11, defines policy-making as "a process of forming, weighing, and evaluating numerous premises in a complex, continually changing and unfolding argument". The premises in these arguments are in effect the assumptions that are made with regard to the stakeholders that are judged to be relevant to the policy issue under consideration. Ref. 10, concurs with Ref. 11, that the notion of policy-making is a process of defining and treating ill-structured issues and problems. An ill-structured problem is characterized as a problem that is well-defined but people responsible for dealing with it can not agree upon a number of issues such as an appropriate solution; a methodology to develop the solution; and on clear definition of the problem objectives and terms. ${ }^{32}$ In sum, policy-making is a process that is

characterized by complexity in nature. In other words, it is a process that deals with organizational problems that by definition can not be formulated; yet affected by unclear and contradictory targets set for the policy goals; let alone solved, independently of one another.

\subsection{Policy-making as a collaborative process}

In real life and nature, organizational policy-making processes are inherently collaborative. This means, policies are created in a policy-making process, which 
involves an iterative and collaborative process requiring an interaction amongst three broad streams of activities: problem definition, solution proposals and a consensus based selection of the line of action to take. A policy-making process is a collaborative design process whose attention is devoted to the structure of the policy, to the context and constraints (concerns) of the policy and its creation process, and the actual decisions and events that occur. ${ }^{31}$ Because of their nature, policy processes have been characterized by complexity. Two kinds of complexity in policy-making processes have been described: multi-participant (also social complexity) complexity, and technical complexity. ${ }^{31,33}$ The two types of complexity have distinguished characteristics/concerns. We aim to examine, and address, those concerns/characteristics that have a collaborative nature. Such concerns as described by various researchers (see Refs. 34, 35, 31, 36, 10, 32) broadly include:

- Degree of variance in interests and tasks required - policy stakeholders will influence the process according to their views and interests due to the demand to have a say with regard to the policy problems and potential solutions yet differing in its views and knowledge;

- Conflicting objectives and criteria - this stems from lack of clear and measurable objectives as a result of failure of alignment of various perceptions from policy stakeholders. The interests of actors and their perceptions of reality determine their objectives, that is, the outcomes they want to achieve;

- Lack of consensus - lack of consensus among policy stakeholders, results from the failure to find common definitions on policy issues due to personal beliefs, attitudes, biases, and perceptions;

- Lack of understanding of the policy problem - policy stakeholders or participants usually start off the process to solve policy problems with a lack of understanding and insight into the policy problem elements and their relationships. This is also affected by lack of sufficient and relevant technical information and data for the formulation of policy;

- Lack of a clear methodology/approach - when given policy assignments, policy stakeholders will often need to design new methods/approaches to tackle them, as adequate approaches/methods to attain satisfactory policy plans do not exist;

- Time pressure - this stems from the fact that organizing participation in policy procedure (as it involves many activities and actors) is hard and time consuming. Because of the large numbers of actors, policy processes most of the time turn out to be highly unpredictable.

Due to the collaborative nature of a policy-making process, its quality is greatly determined by a well-managed collaborative process. We look towards the field of collaboration engineering to be able to deal with such concerns. For example, Figure 2 presents a collaborative policy-making process model that would be used to realize a policy. It includes three broad activities (Identification, Filtering and Prioritizing Key policy solutions), and one decision point. The model focuses attention on the logic flow of the process from activity to activity. To achieve execution of these activities/steps, a collaboration engineer could relate a sequence of collaboration patterns (Generate, Converge, and Evaluate) with respective thinkLets (DirectedBrainstorming, FastFocus, and StrawPoll) to move a group of policy stakeholders toward realizing a satisfactory policy result. 


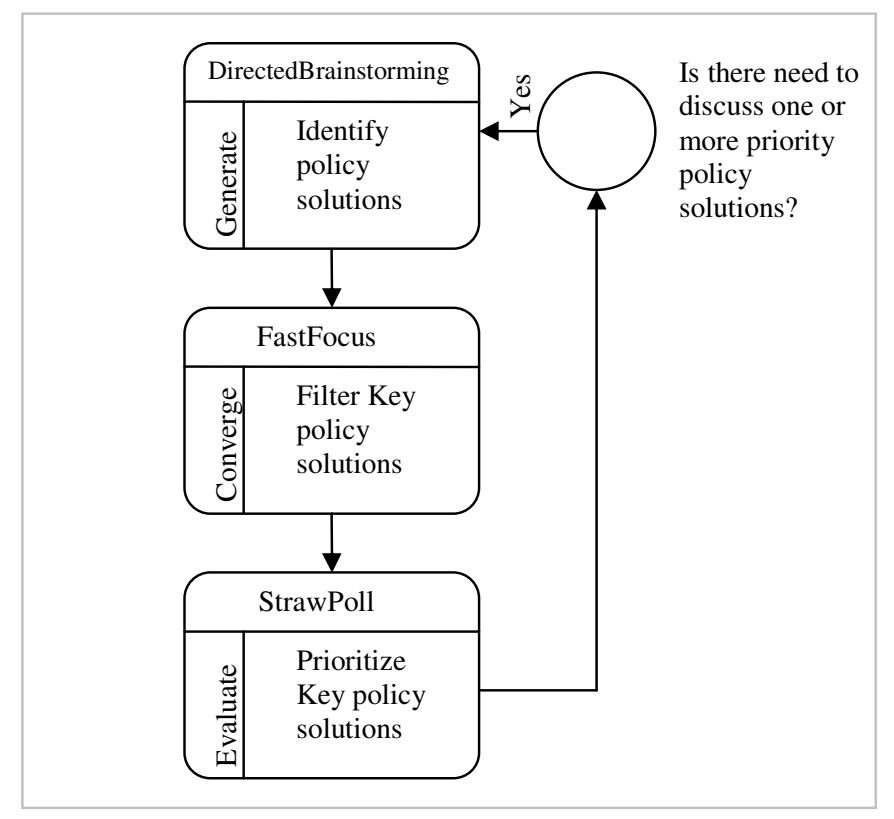

Fig.2. Collaborative Policy-making process example

We have described collaborative concerns related to organizational policy-making processes. These concerns are the motivations for formulating collaborative needs for organizational policy-making processes and therefore the need to invest in collaboration engineering. The collaborative needs formulated and how they can be met by CE include:

- Policy requirements expectation accommodation - policy-making stakeholders need a collaborative process that permits them to contribute and the contributions taken into account in policy requirements negotiation. In other words, there is need for a collaborative process that permits stakeholders to arrive at satisfactory (reach for consensus) policy requirements' outcomes without conflicting and compromising overall policy objectives. In the collaboration engineering approach, execution of collaborative processes permits representation of all the stakeholders in collaborative problem-solving activities; thereby bettering the chance of their interests being accommodated in the solution. ${ }^{1}$

- Understanding of the policy process - there is need for a collaborative process that is not complex and is easily understood by the policy-making practitioners. In collaboration engineering, collaboration engineers use building blocks known as thinkLets when designing repeatable collaboration processes. A thinkLet is a building block that facilitates intervention to improve productivity of and quality of work life for policy practitioners by enabling rapid development of the policymaking collaboration processes. ${ }^{16,37}$ Figure 2, for instance, depicts how execution of process steps/tasks could be achieved. The collaboration engineer uses thinkLets that 
would move a group of policy practitioners to achieve a deliverable. In other words, usage of thinkLets would permit policy practitioners to execute the collaboration policy process with ease, hence making it easily understandable.

- Policy process efficiency - policy-making stakeholders need a collaborative process in which they can take less time and other resources (such as effort and cost) for attainment of the policy than without the use of a collaborative approach. With collaboration, groups tend to minimize/save on the amount of resources required to attain a goal. ${ }^{22}$ For example, the time and effort policy stakeholders will actually use for achieving the planned policy outcomes in a collaboration session.

- Structured policy problem-solving approach - there is need for a standard recurring collaborative process that is to be referred to each time policy stakeholders need to tackle complex policy problems. The model in Figure 2 is an example of such standard recurring collaborative policy processes designed following the $\mathrm{CE}$ approach. That is, CE focuses on recurring processes rather than ad hoc processes where a repeated process if improved, an organization will derive benefit from the improvement again and again. While with ad hoc processes, the value of each process improvement will accrue only once. More so, with the improvement to repeatable processes, the same collaborative policy process could be applied successfully in each policy developing workshop with different groups (policy stakeholders) and focusing on different collaborative policy developing tasks. Also, with the improvement to repeatable processes, practitioners of these processes can learn to conduct them successfully without learning facilitation skills. ${ }^{14,1}$

In addition to the above means of improving collaborative concerns, CE will also benefit organizational policy-making stakeholders through more ways:

- Creating policies is collaborative work, which may require external support from professional policy developing facilitators, and yet they are expensive and scarce; $\mathrm{CE}$ therefore seeks to bring the value of facilitated interventions to people who do not have access to facilitation. ${ }^{15}$ That is, a collaboration engineer designs a repeatable collaboration policy-making process once which can then be carried out by stakeholders involved in the policy-making process without additional support. In sum, CE is a design approach for recurring collaboration processes that can be transferred to groups that can be self-sustaining in these processes using collaboration techniques and technologies. ${ }^{38}$

- Better still, the designs of recurring processes (in our case, designs of collaborative organizational policy processes as seen in Figure 2 example) will create intellectual capital for organizations. ${ }^{1}$ This means, different policy-making practitioners can be able to execute the collaborative organizational policy-making process. Also this collaboration process can be executed for different teams of the same organization. More so, the same collaborative organizational policy-making process can be used for different types of policies (content).

In sum, the collaborative needs formulated above are the basis for the derivation of the domain indicators for evaluating quality collaborative organizational policy-making processes. The section that follows gives the description of the evaluation instrument.

\section{Collaborative Policy-Making Processes Evaluation Instrument}

\subsection{Overview of existing Evaluation Frameworks}


Organizational stakeholders often face problems that are sufficiently challenging and complex that no single individual can accomplish the task alone. ${ }^{39}$ We have looked at CE as an approach that can better support such problems. An organization is a social unit that occasionally establishes organizational policies because of internal business needs. It is important for organizations to create policies for a number of reasons: they establish responsibilities and accountability; they help ensure compliance and reduce institutional risk; they may be needed to establish and/or defend a legal basis for action; and they provide clarification and guidance to the organizational community. ${ }^{40}$ Policies are created through policy-making processes. By their nature, policy-making processes are characterized by complexity. That is, policy processes deal with organizational problems that by definition can not be formulated; yet affected by unclear and contradictory targets set for the policy goals; let alone solved, independently of one another.

Because of the complexity involved in policy-making processes, several researchers of Policy Analysis studies (see Ref. 33), developed quality frameworks to evaluate the policy meeting process. For a complete overview of the criteria as discussed by the researchers, we refer to Ref. 41, in Ref. 33. The criteria involves: (i) policy process criteria - evaluation criteria that measure participation of policy stakeholders and problem solving process characteristics such as cost and methodology; (ii) policy outcome criteria - objective quality of the final policy study or policy theory, the satisfaction of participants with the outcomes achieved and the measure in which the policy solution fits the questions posed; and (iii) policy impact and success criteria - impact criteria measuring the usage of the policy support by the policy makers and the success of the policy in solving the policy problems. However, according to Ref. 33, these criteria did not take care of the problem owner and participating stakeholders' opinions about the meeting process, its outcome and impact. As a result, Ref. 33, used Group Support Systems to support policy meetings and the evaluations were improved as follows: (i) satisfaction with the meeting process by problem owner and participating stakeholders; (ii) confirmation of the added value of a GSS to support the meeting expressed by the problem owner; (iii) satisfaction with the meeting outcomes expressed by the problem owner and participating stakeholders; and (iv) confirmation of positive impact on the policy process expressed by the problem owner.

With regard to the above contributions, we acknowledge that the existing research offers policy meeting criteria frameworks. Unfortunately, this literature does not or scantly explains concrete guidelines of how to conduct an evaluation of a successful collaborative organizational policy-making process. In real life and nature, organizational policy-making processes are inherently collaborative, therefore should be able to yield value to organizations that make them. To this end we turn to collaboration engineering (CE) for their better support leading to improved collaborative organizational policymaking processes (CPMP). In other words, the collaborative needs met by CE (see section 4.3) are the basis for the derivation of the domain indicators/constructs for evaluating collaborative organizational policy-making processes as seen in the subsection below. 


\subsection{Domain Indicators for Collaborative Organizational Policy-making Processes}

Since we feel that CE has the potential to improve collaborative organizational policymaking processes, we constructed definitions with respective measurement means (see Table 3) and operationalization tools examples of possible evaluation domain indicators/constructs of such processes. We have applied, measured and operationalized these indicators. We focused on the application of collaboration engineering to improve the quality of Business-IT alignment related policy-making processes. Specifically, we aimed at examining, and addressing concerns that have a collaborative nature and are related to Business-IT alignment issues. A key element in our results based on case studies conducted, involved an initial design of a generic collaborative policy-making process for Business-IT alignment purposes. The design applied elementary constructs from the collaboration engineering approach. Based on the results, the quality of the generic policy-making process, in terms of its effectiveness, efficiency, applicability, and satisfaction with process outcomes proved to be a success. As such, we concluded that the collaborative process has indeed the potential to support organizations in developing quality policies to achieve Business-IT alignment. ${ }^{42}$

To avoid reputation, the domain indicators together with the $\mathrm{CE}$ general indicators (see Table 1) form the overall evaluation instrument for collaborative organizational policy-making processes. Nevertheless, definitions of the CE general indicators can be customized to suit specific policy domain contexts, for example, we define policy process efficiency indicator "as the collaborative policy-making process should take stakeholders less time for attainment of the policy than without the use of a collaborative approach". We therefore base our evaluation instrument on the collaborative needs deduced from collaborative concerns identified in organizational policy-making processes described above. Also the existing policy evaluation frameworks do not specifically look at ways of conducting a successful (quality) collaborative policy-making process effort:

- Policy requirements expectation accommodation/policy requirements negotiation

- Completeness of the policy process outcomes

- Degree of applicability of standard policy process

- Stakeholders' ease of common policy elements identification (with their definitions)

- Ease of understanding of the policy process

Table 3. Definitions of Collaborative Organizational Policy-making Process (CPMP) indicators

\begin{tabular}{|c|c|c|c|}
\hline $\begin{array}{l}\text { CPMP } \\
\text { Indicator }\end{array}$ & Definition(s) & $\begin{array}{l}\text { Measurement } \\
\text { (Examples) }\end{array}$ & $\begin{array}{l}\text { Operationalizatio } \\
\text { n Tool(s) } \\
\text { (Examples) }\end{array}$ \\
\hline $\begin{array}{l}\text { Policy } \\
\text { requirements } \\
\text { expectation } \\
\text { accommodation/ne } \\
\text { gotiation }\end{array}$ & $\begin{array}{l}\text { The ability of the process to } \\
\text { accommodate awareness of } \\
\text { each stake holder's desired } \\
\text { policy preferences (ability to } \\
\text { contribute and the } \\
\text { contributions taken into } \\
\text { account in policy }\end{array}$ & $\begin{array}{l}\text { (i).Number of key satisfactory } \\
\text { contributions per each } \\
\text { stakeholder taken into account } \\
\text { Versus total number of } \\
\text { contributions from all } \\
\text { stakeholders } \\
\text { (ii).Total number of key } \\
\text { satisfactory contributions yet } \\
\text { match with overall policy } \\
\text { objectives }\end{array}$ & $\begin{array}{l}\text { i). Session outcome } \\
\text { questionnaires with } \\
\text { participants, and } \\
\text { problem owner } \\
\text { ii). Transcribing } \\
\text { reports/data logs to } \\
\text { determine quality of } \\
\text { results from the } \\
\text { process } \\
\text { iii). Voting sheets }\end{array}$ \\
\hline
\end{tabular}




\begin{tabular}{|c|c|c|c|}
\hline & $\begin{array}{l}\text { requirements negotiation). In } \\
\text { other words, the process } \\
\text { should permit stakeholders to } \\
\text { arrive at satisfactory policy } \\
\text { requirements' outcomes } \\
\text { without conflicting and } \\
\text { compromising overall policy } \\
\text { objectives }\end{array}$ & $\begin{array}{l}\text { (iii). The extent to which key } \\
\text { satisfactory contributions per } \\
\text { each stakeholder are taken into } \\
\text { account }\end{array}$ & $\begin{array}{l}\text { (figures) to determine } \\
\text { levels of } \\
\text { agreement/consensus }\end{array}$ \\
\hline $\begin{array}{l}\text { Completeness of } \\
\text { the policy process } \\
\text { outcomes }\end{array}$ & $\begin{array}{l}\text { The ability of the } \\
\text { stakeholders to fulfill and } \\
\text { with relevant information for } \\
\text { each of the elements of the } \\
\text { policy outcomes }\end{array}$ & $\begin{array}{l}\text { The extent to which there is } \\
\text { more agreement among policy } \\
\text { stakeholders to arrive at } \\
\text { mutually acceptable policy } \\
\text { outcomes yet match the policy } \\
\text { objectives }\end{array}$ & $\begin{array}{l}\text { i). Voting sheets } \\
\text { (figures) to determine } \\
\text { levels of } \\
\text { agreement/consensus } \\
\text { ii). Transcribing } \\
\text { reports/data logs to } \\
\text { determine } \\
\text { completeness of } \\
\text { results from the } \\
\text { process }\end{array}$ \\
\hline $\begin{array}{l}\text { Degree of } \\
\text { applicability of } \\
\text { standard policy } \\
\text { process }\end{array}$ & $\begin{array}{l}\text { The extent to which a } \\
\text { standard collaborative policy } \\
\text { process can be applied to } \\
\text { varying policy types }\end{array}$ & $\begin{array}{l}\text { The extent to which the same } \\
\text { collaborative policy process can } \\
\text { accommodate (develop) varying } \\
\text { policy types }\end{array}$ & $\begin{array}{l}\text { i). Direct } \\
\text { observations } \\
\text { ii). Focused } \\
\text { interviews with } \\
\text { participants, problem } \\
\text { owner } \\
\text { iii). Documentary } \\
\text { analysis }\end{array}$ \\
\hline $\begin{array}{l}\text { Stakeholders' ease } \\
\text { of common policy } \\
\text { elements } \\
\text { identification } \\
\text { (with their } \\
\text { definitions) }\end{array}$ & $\begin{array}{l}\text { The ability of stakeholders to } \\
\text { identify and have a common } \\
\text { understanding of the policy } \\
\text { elements (with their } \\
\text { definitions) }\end{array}$ & $\begin{array}{l}\text { The extent to which there is } \\
\text { agreement among policy } \\
\text { stakeholders on policy elements } \\
\text { (with their definitions) }\end{array}$ & $\begin{array}{l}\text { i). Voting sheets } \\
\text { (figures) to determine } \\
\text { levels of } \\
\text { agreement/consensus } \\
\text { ii). Session outcome } \\
\text { questionnaires with } \\
\text { participants, and } \\
\text { problem owner } \\
\text { iii). Focused } \\
\text { interviews with } \\
\text { problem owner }\end{array}$ \\
\hline $\begin{array}{l}\text { Ease of } \\
\text { understanding of } \\
\text { the policy process }\end{array}$ & $\begin{array}{l}\text { The collaborative policy } \\
\text { process should not be } \\
\text { complex and should be easily } \\
\text { understood by the } \\
\text { policymaking stakeholders, } \\
\text { i.e. the process should permit } \\
\text { stakeholders to have the } \\
\text { knowledge of the goals and } \\
\text { perceptions of the policy } \\
\text { process to derive satisfactory } \\
\text { results }\end{array}$ & $\begin{array}{l}\text { The number of times the } \\
\text { collaboration policy process is } \\
\text { executed with ease by the } \\
\text { stakeholders }\end{array}$ & $\begin{array}{l}\text { i). Session process } \\
\text { questionnaires with } \\
\text { participants, and } \\
\text { problem owner } \\
\text { ii). Direct } \\
\text { observations } \\
\text { iii). Focused } \\
\text { interviews with } \\
\text { participants }\end{array}$ \\
\hline
\end{tabular}

Using the constructs defined in Tables 1 and 3, respectively, it would be important for us to reflect about their relationships when evaluating quality improvement in collaborative policy processes and their outcomes. Because description of construct relationships is beyond the scope of this paper, we illustrate some examples here. 


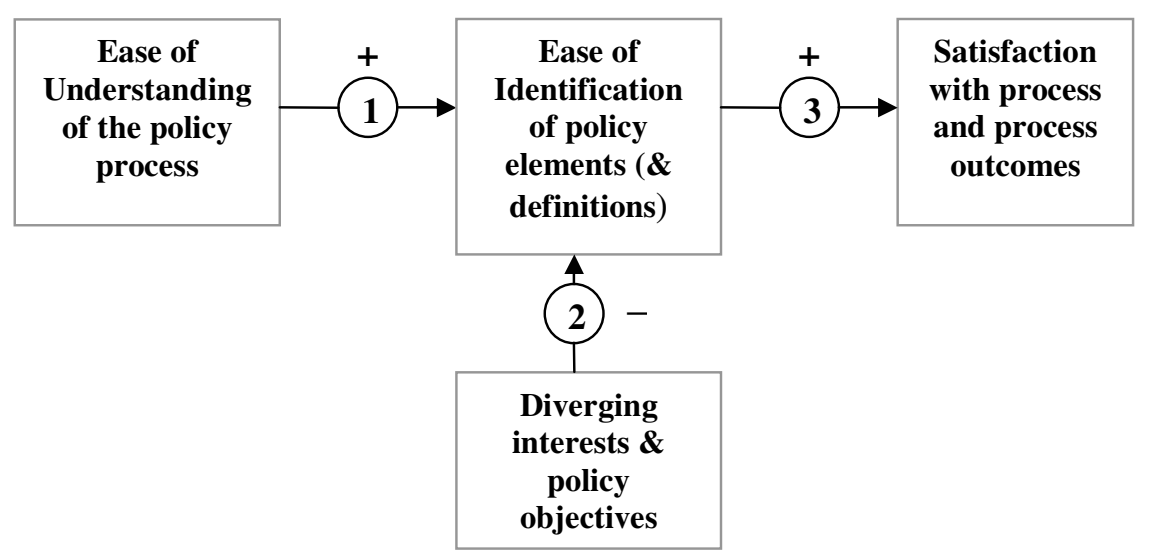

Fig. 3: Example of relationship model among CPMP constructs

In Figure 3, for example, we use a box-and-arrow model to illustrate several theoretical propositions to explain stakeholders' Satisfaction with process and process outcomes in a collaborative policy making process evaluation. Each box-arrow-box combination represents a proposition. The direction of the arrow indicates the direction of causation, and the plus (+) and minus (-) signs on the arrows indicate positive and negative relationships, respectively. The model posits Satisfaction with process and process outcomes as a positive function of ease of Identification of common policy elements (with their definitions) via proposition 3. It posits ease of Identification of common policy elements (with their definitions) as a positive function of ease of Understanding of the policy process via proposition 1, and as a negative function of Diverging interests \& policy objectives via proposition 2 . In other words, the more ease of understanding of the policy process by the stakeholders, the more ease of identification of common policy elements (with their definitions), which in turn increases more satisfaction with the policy process and process outcomes.

While proposition 2, the diverging interests \& policy objectives proposition posits an inverse relationship rather than a positive relationship. That is, the more a group experiences diverging interests \& policy objectives, the less it will be able to identify common policy elements towards satisfactory policy outcomes. In short, the constructs do not always follow a linear relationship. We should note, however, that resources used to improve one outcome will not automatically improve another. For instance, a resource that improves satisfaction does not necessarily cause policy stakeholder commitment; nor does a resource that produces high levels of commitment automatically produce high levels of acceptance and ownership of the policy process outcomes. Hence, if these outcomes have different causes, then separate relation/theory models would be suggested for each of these outcomes. This is in line with Ref. 43. 


\section{Conclusions}

Evaluating collaboration processes is a vital activity in the CE approach since it leads to maximizing purposeful effort. In this paper, we have seen that collaboration processes once designed, they should be able to yield value for the organization for which they are designed. This has been illustrated in the CE evaluation instrument provided. In this instrument, both general and domain specific indicators, as well as examples of their measurement means and operational tools have been presented. Specifically, we present an evaluation instrument that can be used by organizational policy-making stakeholders to benchmark and perform an assessment of a collaboration intervention, thus supporting continuous improvement of their collaborative policy-making processes. To get started (to use the evaluation instrument), organizational policy-making stakeholders will need to first read, understand and decide when to apply the constructs provided. Then, they will need to identify the purpose for which they need to evaluate the collaboration process. In other words, stakeholders need to identify what determines the success of their collaboration session. There are various ways on which to base the evaluation criteria, among these include: deliverables that a policy problem owner wants to achieve, collaboration session participants' deliverables, goal of the collaboration process, to mention but a few. Depending on what criteria to take, policy stakeholders will then use the instrument to identify constructs/indicators with respective measurement means and operational tools that can enable them accomplish their goal.

While meaningful work on possible strategies and measurements for designed collaboration processes, and with respect to collaborative organizational policy-making processes has been made, there is need for additional research and particularly with its applicability to organizational policy-making to be accomplished. For the collaborative organizational policy-making evaluation instrument, much work remains to refine the list of indicators and multi-criteria basis for data collection that can be applied in the field. This research is in progress.

With respect to the "domain specific indicators" evaluation instrument (see Table 2), when one looks at these indicators for each domain closely, you may realize that some of them do appear in all domains, though they are particular to suit given domain context; more so, the indicators could be applicable to all domains. For future research therefore, we suggest developing an evaluation instrument that encompasses all domain indicators into one, where the indicator should be applicable to all domains, but instantiated to reflect a given situation or domain context. A further reflection should be on formalization of relationships of the evaluation constructs. As a next step therefore, we are working towards a more theoretical foundation of the construct relationships.

\section{References}

1. G.J. de Vreede and R.O. Briggs, Collaboration Engineering: Designing Repeatable Processes for High-Value Collaborative Tasks, in Proc. of the 38th Hawaiian International Conference on System Sciences, IEEE Computer Society Press (Los Alamitos, Hawaii 2005) 
2. J.F. Nunamaker, jr., R.O. Briggs., G.J. de Vreede, From Information Technology to Value Creation Technology, (eds). Dickson, G.W., DeSanctis, G. Information Technology and the Future Enterprise, (New York, Prentice-Hall, 2001)

3. M.M. Shepherd, R.O. Briggs, B.A. Reinig, J. Yen, J.F. Jr. Nunamaker, Social Comparison To Improve Electronic Brainstorming: Beyond Anonymity, Journal of MIS, 12, 3, (1996), 155 170

4. M. Scriven, Evaluation Thesaurus (Newbury Park, CA: Sage, 1991)

5. P. H. Rossi and H. E. Freeman, Evaluation: A Systematic Approach (5th ed.) (Newbury Park, CA: Sage Publications, Inc. 1993)

6. M. Trochim, William, The Research Methods Knowledge Base, $2^{\text {nd }}$ ed., (2005), http://trochim.human.cornell.edu/kb/index.htm

7. E. Vedung, Public Policy and Program Evaluation (London, Transaction Publishers, 1997)

8. D. Stufflebeam, Checklists development checklist (2000), www.wmich.edu/evalctr/checklists/

9. M. Hengst den, G.L. Kolfschoten., D. L. Dean., and A. Chakrapani, Assessing the Quality of Collaborative Processes, Proceedings of the 39th Hawaii International Conference on System Sciences, (Big Island, Hawaii, IEEE, 2006)

10. H. Mintzberg, D. Raisingham, and A., Theoret, The Structure of Unstructured Decision Processes, Administrative Science Quarterly, 21, (1976), 246-275

11. I. Ian, Mitrof, Stakeholders of the Organizational mind: Toward a new view of organizational policy making, (Jossey-Bass Inc., Publishers, San Francisco, California, 1983)

12. G.J. de Vreede and R.O. Briggs, Meetings of the Future: Enhancing Group Collaboration with Group Support Systems, Journal of Creativity \& Innovation Management, 6(2), (1997), 106116

13. P.S. Seligmann, G.M. Wijers and H.G. Sol, Analyzing the Structure of IS Methodologies, In: Proceedings of the Proceedings of the 1st Dutch Conference on Information Systems, (Amersfoort, Netherlands, 1989)

14. R.O. Briggs., G.L. Kolfschoten, G.J. de Vreede and D. L. Dean, Defining Key Concepts for Collaboration Engineering, In Proceedings of the 12th Americas Conference on Information Systems (AMCIS), Mexico, 2006

15. R.O. Briggs, G.J. de Vreede, and J.F. Nunamaker, jr., Collaboration Engineering with ThinkLets to Pursue Sustained Success with Group Support Systems, Journal of Management Information Systems, 19 (4), (2003), 31-63

16. G.J. de Vreede, G.L. Kolfschoten and R.O. Briggs, Thinklets: a collaboration engineering pattern language, Int. J. Computer Applications in Technology, 25, Nos. 2/3, (2006), 140-154

17. B. Boehm, P. Grünbacher, and R.O. Briggs, Developing Groupware for Requirements Negotiation: Lessons Learned. IEEE Software, 18 (3), (May/June, 2001), 46-55

18. R.O. Briggs and P. Grünbacher, EasyWinWin: Managing Complexity in Requirements Negotiation with GSS, Proceedings of the $35^{\text {th }}$ Hawaii International Conference on System Sciences, (IEEE, 2002), pp. 1-10

19. A. L. Fruhling, and G.J. de Vreede, Collaborative Usability Testing to Facilitate Stakeholder Involvement, eds. S. Biffl, A. Aurum, B. Boehm, H. Erdogmus, P. Grünbacher, Value Based Software Engineering, Berlin: Springer-Verlag, (2005), pp. 201-223

20. M. Kamal,, A. J. Davis, J. Nabukenya, T.V. Schoonover, L.R. Pietron and G.J. de Vreede, Collaboration Engineering for Incident Response Planning: Process Development and Validation. Eds. Jr. Sprague, H. Ralph, Proceedings of the 40th Hawaii International Conference on System Sciences, (Big Island, Hawaii: IEEE 2007), pp. 1-10

21. G.J. de Vreede, P. G. Koneri,, D. L. Dean, A. L. Fruhling, and P. Wolcott, A Collaborative Software Code Inspection: The Design and Evaluation of a Repeatable Collaboration Process in the Field, International Journal of Cooperative Information Systems, 15(2), (2006), 205228

22. R.O. Briggs, G.J. de Vreede and B.A. Reinig, A theory and measurement of meeting satisfaction, Proceedings of the 36th Hawaii International Conference on System Sciences, Hawaii, (IEEE Computer Society Press, 2003) 
23. R.O. Briggs, The Focus Theory of Group Productivity and its Application to the Design, Development, and Testing of Electronic Group Support Technology, (PhD Thesis, University of Arizona, 1994)

24. R.O. Briggs, M. Adkins, D.D. Mittleman, J. Kruse, S. Miller, and J.F. Nunamaker, jr., A technology transition model derived from qualitative field investigation of GSS use aboard the U.S.S. CORONADO, Journal of Management Information Systems, 15 (3), (1998-1999), 151 195.

25. S. Robbins, R. Bergman and I. Stagg, Management, (Prentice-Hall, Australia Pty Ltd., Prentice-Hall, Sydney, USA 1997)

26. R. Rose, e., Policy Making in Great Britain, (Macmillan, London, Great Britain, 1969)

27. J.E. Anderson, Public Policy-making, (Rimehart and Winston, New Holt, USA, $2^{\text {nd }}$ ed., 1979)

28. J.E. Anderson, Public Policy-making: An Introduction, Houghton Mifflin, Boston, USA, $5^{\text {th }}$ ed., 2003)

29. A.L. Schneider and H. Ingram, Policy Design for Democracy (University Press of Kansas, Lawrence, Kansas, USA, 1997)

30. J. Nabukenya, Collaboration Engineering for Policy Making: A Theory of Good Policy in a Collaborative Action, eds., H. Bounif, Proceedings of the $12^{\text {th }}$ Doctoral Consortium, held in conjunction with the $17^{\text {th }}$ Conference on Advanced Information Systems Engineering (CAiSE’05), (Portal, Portugal, 2005), pp. 54-61

31. P.A. Sabatier, Theories of the Policy Process, (West view Press, Boulder, Co., 1999)

32. R. L. Ackoff, Redesigning the Future, (New York: Wiley, 1974)

33. C.v. Herik d., Group Support for Policy Making, (PhD thesis, Delft University of Technology, Delft, Netherlands, 1998)

34. O. van Riet de, Policy Analysis in Multi-Actor Policy Settings: Navigating between negotiated non-sense and superfluous knowledge, (PhD thesis, Delft University of Technology, Delft, Netherlands, 2003)

35. A. Roelofs, Structuring Policy Issues: Testing a mapping technique with Gaming/Simulation, (PhD thesis, Proefschrift Katholieke Universiteit Brabant, Tilburg, Netherlands, 2000)

36. C. Eden, S. Jones and D. Sims, Messing about in Problems: an informal structured approach to their identification and management, (Pergamon Press, Oxford, Great Britain, 1983)

37. G.L. Kolfschoten, R.O. Briggs, G.J. de Vreede, P.H.M. Jacobs, and J.H. Appelman, Conceptual Foundation of the ThinkLet Concept for Collaboration Engineering. Intl Journal of Human Computer Science (2006)

38. G.L. Kolfschoten, R.O. Briggs, J.H. Appelman, G.J. de Vreede, ThinkLets as Building Blocks for Collaboration Processes: A Further Conceptualization, Lecture Notes in Computer Science, ed. Springer Verlag (Berlin, 2004)

39. H. Mintzberg, Structures in Fives, (Prentice-Hall, Englewood cliffs, NJ, 1983)

40. M.T. Ford and P. Spellacy, Policy development: In theory and practice, In: Tuesday, July 12, Baltimore, MD, July 9-12, 2005, (National Association of College and University Business Officers, 2005 Annual Meeting)

41. W.A.H. Thissen, R. Bras, E. Daalen van, C.W. Herik van,., H.C. Speel, D. Tijink, and P. Twaalfhoven, Kwaliteitbepaling van beleidsanalystische studies, (Delft University of Technology, Delft, 1997)

42. J. Nabukenya, P. Bommel van and H. A. Proper, Collaborative IT Policy-making as a means of achieving Business-IT Alignment, eds. B. Pernici, J. A. Gulla,, Proceedings of the Workshop on Business/IT Alignment and Interoperability (BUSITAL'07), held in conjunction with the $19^{\text {th }}$ Conference on Advanced Information Systems Engineering (CAiSE'07), vol. 1, (Trondheim, Norway, 2007) pp. 461-468

43. R. O. Briggs, On Theory-Driven Design and Deployment of Collaboration Systems, Lecture Notes in Computer Science 3198, Springer-Verlag, (Berlin, Germany, 2004) 